\title{
Long-term retention of fear-potentiated startle following a short training session
}

\author{
SERGE CAMPEAU, KENG C. LIANG, and MICHAEL DAVIS \\ Yale University School of Medicine, New Haven, Connecticut \\ and the Ribicoff Research Facilities of the Connecticut Mental Health Center \\ New Haven, Connecticut
}

\begin{abstract}
The permanence of aversive memories has been reported to vary when assessed with conditioned emotional response procedures (months) versus avoidance response measures (days). When evaluated with the potentiated startle paradigm, five light-shock pairings at a 2-min intertrial interval produced highly reliable potentiated startle, which was similar in magnitude from 1 to 28 days after training and maximal using a $0.6-\mathrm{mA}$ footshock intensity. These results are consistent with such measures as conditioned emotional response procedures, in which aversive memories have been observed after months following original training. The results obtained with various shock intensities are also discussed in the context of other indices of fear.
\end{abstract}

Acquisition of fear is generally believed to depend on Pavlovian conditioning processes (W. R. McAllister \& D. E. McAllister, 1971). That is, conditioned stimuli (CSs) come to elicit defense reactions only when appropriately paired with noxious unconditioned stimuli (USs). One of the distinguishing characteristics of conditioned fear is that it can be demonstrated in avoidance tasks (Quartermain \& Judge, 1983; Quartermain \& Jung, 1989), conditioned emotional response (CER) procedures (Brophy \& Tremblay, 1971; Gleitman \& Holmes, 1967; Leaf \& Muller, 1965; Mahoney \& Ayres, 1976), conditioned freezing measures (Blanchard \& Blanchard, 1969; Fanselow \& Bolles, 1979), and the potentiated startle paradigm (Brown, Kalish, \& Farber, 1951; Davis, Schlesinger, \& Sorenson, 1989) after very few, and often single, CS-US pairings.

One aspect of Pavlovian fear conditioning that has apparently received little experimental analysis is its expression (memory) after various intervals between a small number of CS-US pairings and a retention test (Flaherty, 1985; Gleitman, 1971; Spear, Miller, \& Jagielo, 1990). Furthermore, conflicting results in regard to the permanence of aversive memories have been reported when retention was assessed with different performance measures (W. R. McAllister \& D. E. McAllister, 1971). For

\footnotetext{
This research was supported by National Institute of Neurological Disorders and Stroke Grant NS-18033, Research Scientist Development Award MH-00004 to Michael Davis, National Institute of Mental Health Grants MH-25642 and MH-41298, a grant from the Air Force Office of Scientific Research, and the State of Connecticut. We thank Lee Schlesinger, who tested the rats, and William Falls for his comments on an earlier draft of this manuscript. Correspondence concerning this article should be addressed to Michael Davis, Department of Psychiatry, Yale University School of Medicine, 34 Park Street, New Haven, CT 06508 .
}

instance, rats tested in a CER task after a single CS-US pairing demonstrated comparable performance 1 and 29 days after original training (Shurtleff \& Ayres, 1981). Four CS-US pairings have been shown to produce comparable CER $24 \mathrm{~h}$ and 90 days after training (Gleitman \& Holmes, 1967). On the other hand, avoidance measures revealed significant performance decrements 14 days after three CS-US pairings in mice (Quartermain \& Judge, 1983; Quartermain \& Jung, 1989). Even after as many as 35 CS-US pairings, rats tested on avoidance measures show significantly lower retention performance a few days after original training (D. E. McAllister \& W. R. McAllister, 1968; Spear, Hamberg, \& Bryan, 1980). Such results support the view that different measures of fear do not always correlate with each other, even though they are assumed to reflect a unitary central state of fear (W. R. McAllister \& D. E. McAllister, 1971). Therefore, generalizations about the permanence of aversive memories assessed with different fear measures should not be made without experimental analysis.

One measure of fear routinely employed in our laboratory is the potentiated startle paradigm, in which the amplitude of the acoustic startle reflex is enhanced in the presence of a light CS previously paired with footshocks (Brown et al., 1951; Davis \& Astrachan, 1978). Although potentiated startle has been reported as long as 21 days after 20 CS-US pairings in original training (Cassella \& Davis, 1985), no study has systematically examined the relative level of potentiated startle at different retention intervals. On the basis of the above considerations, we decided to study the effects of various training-to-testing intervals with the potentiated startle paradigm after rats were conditioned with a relatively small number (five) of CS-US pairings. Also, different footshock intensities were used to assess possible improvements in the magnitude of fear-potentiated startle after five training trials. 


\section{EXPERIMENT 1A}

The purpose of this experiment was to provide evidence that an eventual startle enhancement would be produced by associative, as opposed to nonassociative (pseudoconditioning), learning processes. The parameters used were partly determined from a previous study (Davis et al., 1989).

\section{Method}

\section{Subjects}

The subjects were 20 experimentally naive male albino SpragueDawley rats weighing $300-400 \mathrm{~g}$ (Charles River Co.). They were housed in wire cages $(17 \times 35 \times 45 \mathrm{~cm})$ in groups of 5 , with water and laboratory chow continuously available, and maintained on a 12:12-h light:dark cycle (lights on at 7:00 a.m.). The rats were acclimated to the colony rooms for 2 to 3 weeks before training began.

\section{Apparatus}

Training apparatus. Five identical boxes $(30 \times 25 \times 25 \mathrm{~cm})$, constructed of aluminum sides and tops and clear Plexiglas front and back walls, were located on two shelves within a ventilated, sound-attenuating chamber $(2.5 \times 2.5 \times 2 \mathrm{~m}$; Industrial Acoustic Co.). The floors consisted of stainless steel rods, $4.5 \mathrm{~mm}$ in diameter and spaced $19 \mathrm{~mm}$ apart. Background noise of $55 \mathrm{~dB}$ (SPL) was provided by a white-noise generator. Sound-level measurements were made with a General Radio Model 1551-C sound-level meter (A scale). The visual CS was produced by an 8-W fluorescent light bulb ( $100 \mu \mathrm{sec}$ rise time) located just outside of the back wall of each training box, which was kept entirely dark except when the CS was on. The footshock USs were delivered from five LeHigh Valley constant-current shock generators (SGS-004) located outside the chamber. Current intensity was measured with a $1-\mathrm{k} \Omega$ resistor across a differential amplifier of an oscilloscope in series with a $100-\mathrm{k} \Omega$ resistor connected between adjacent floor bars in each of the boxes. Current was defined as the root mean square voltage across a $1-\mathrm{k} \Omega$ resistor $(\mathrm{mA}=0.707 \times 0.5 \times$ peak-to-peak voltage $)$.

Testing apparatus. The boxes used to measure the amplitude of startle responses were five separate stabilimeter devices, as described previously by Cassella and Davis (1986). Briefly, each stabilimeter consisted of a $8 \times 15 \times 15 \mathrm{~cm}$ Plexiglas and wire mesh cage suspended within a $25 \times 20 \times 20 \mathrm{~cm}$ heavy steel frame. Within this frame, the cage was compressed between four springs above and a $5 \times 5 \mathrm{~cm}$ rubber cylinder below, with an accelerometer (M. B. Electronics Type 302) located between the bottom of the cage and the top of the rubber cylinder. Cage movement resulted in displacement of the accelerometer, the output of which was amplified (M. B. Electronics Model N504) and fed to a PDP-11 computer. Startle amplitude was defined as the maximum accelerometer voltage that occurred during the first $200 \mathrm{msec}$ after the startle stimulus was delivered and was proportional to the amplitude of the rat's startle response. The stabilimeters were housed in a chamber (International Acoustic Co.) similar to the one containing the training chambers. The startle stimuli were delivered by high-frequency speakers (Radio Shack Supertweeter) located $10 \mathrm{~cm}$ from each stabilimeter. The stimuli were 50 -msec bursts of white noise, having a rise-decay time of $5 \mathrm{msec}$. The intensities used could be varied. Background noise, provided by a white-noise generator, was $55 \mathrm{~dB}$ (SPL).

\section{Procedure}

Matching. On the first 2 days, the animals were placed in the stabilimeter cages and, 5 min later, presented with 30 noise bursts at a 30-sec interstimulus interval (ISI). Intensities of 90,95 , and $105 \mathrm{~dB}$ were used with 10 noise bursts at each intensity. Noise bursts were presented in a balanced, irregular order, with the restriction that each of the three intensities had to occur in every three trial blocks. The mean amplitude startle across the $\mathbf{3 0}$ noise bursts on the last matching day was used to assign the animais into groups of 5 rats each with similar means before training began.

Training. On the day after the last matching session, the animals were placed in the training cages and, 15 min later, paired animals $(n=10)$ received five CS-US presentations, using a 3.7- $\mathrm{sec}$ light CS coterminating with a $0.5-\mathrm{sec}, 0.6-\mathrm{mA}$ footshock US. The intertrial interval was $2 \mathrm{~min}$. The rats were removed from the cages 5 min after the last CS-US presentation and returned to the colony room. Unpaired animals $(n=10)$ were treated similarly, except that the CS preceded the US by $1 \mathrm{~min}$.

Testing. Three days after training, all of the animals were returned to the testing cages and presented with a total of $70100-\mathrm{dB}$ noise bursts at a 30 -sec intertrial interval; 10 initial bursts, followed by 10 noise bursts at each of three different light-noise intervals $(800$, 1,600 , and $3,200 \mathrm{msec}$ ), intermixed with 30 additional noise bursts. Noise bursts were presented in a balanced, irregular order, with the restriction that each of the four trial types had to occur in every six-trial block (one of each light-noise trial type [three] and three noise-alone trials). Different light-noise intervals were used during testing because previous data have shown that animals trained with a small number of CS-US pairings often show maximum potentiation at test intervals that differ from the training interval (Davis et al., 1989).

\section{Results and Discussion}

An analysis of variance (ANOVA) was performed on the mean difference scores for each test interval $(800$, 1,600 , and $3,200 \mathrm{msec}$ ). These scores were computed by subtracting the mean startle amplitude on the noise-alone trials from that on the light-noise trials for each rat. There were no significant effects of test interval; therefore, the three light-noise intervals were averaged for further analyses and data presentation $[F(2,36)=0.50]$. This result is consistent with the results obtained by Davis et al. (1989), in which five training trials at a 3,200-msec CS-US delay interval produced comparable potentiated startle at 800- and 3,200-msec light-noise test intervals (a 1,600-msec interval was not used in the latter study). Figure 1 shows the mean amplitude startle response of the noise-alone and light-noise trials averaged across the testing session and the difference scores for the paired and unpaired groups. An ANOVA was conducted using trial type (noise-alone and light-noise) as a within-subjects factor and group (paired and unpaired) as a betweensubjects variable. Five CS-US pairings produced significant fear potentiation in the paired group, as revealed by a significant group $\times$ trial type interaction $[F(1,18)=$ 22.24, $p<.001]$. Subsequent dependent $t$ tests on the mean noise-alone and light-noise trials for each group confirmed a reliable potentiation in the paired group only $[t(9)=4.35, p<.01]$.

Significant fear-potentiated startle was revealed only in the paired animals using an intertrial interval of $2 \mathrm{~min}$ during the training phase. This result is consistent with an earlier report in which five trials at an average intertrial interval of 4 min produced reliable potentiated startle (Davis et al., 1989). 


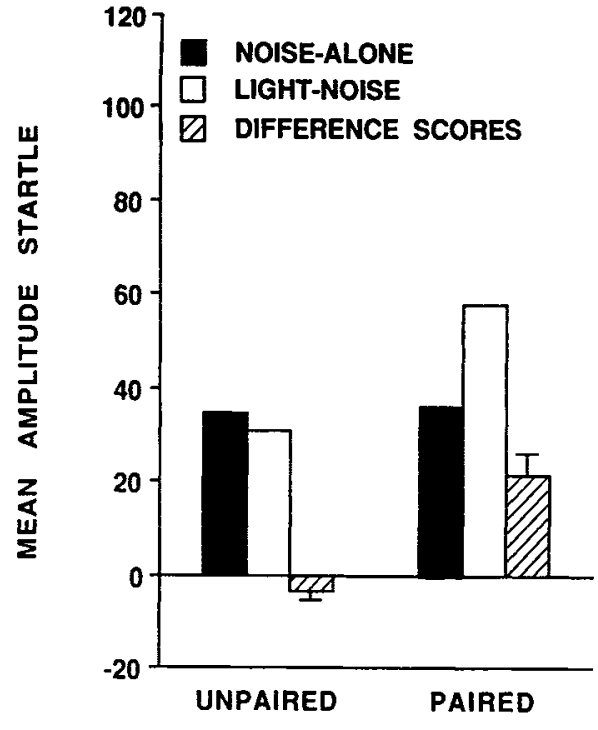

TRAINING CONDITION

Figure 1. Mean amplitude startle on the noise-alone and light-noise test trials and difierence scores $( \pm S E M)$ of rats exposed to five paired or unpaired lights and shocks.

\section{EXPERIMENT 1B}

Demonstration of the associative nature of fear potentiation in Experiment 1A allowed the determination of fear potentiation at different retention intervals.

\section{Method}

Subjects

Sixty experimentally naive rats were used.

\section{Procedure}

The matching, training, and testing procedures, as well as the apparatus, were identical to those used in Experiment 1A. However, different groups of animals ( $n=10$, in each group) were trained with paired presentations of the light and a $0.6-\mathrm{mA}$ footshock, but were tested at intervals of $1,3,7,10,14$, or 28 days after training.

\section{Results and Discussion}

An ANOVA revealed that the mean difference scores were not reliably different at the three light-noise intervals $[F(2,108)=0.55]$. Therefore, averages collapsed over the three intervals were used for the following data presentation and analyses. Figure 2 presents the potentiated startle obtained at different retention intervals. This figure shows that fear-potentiated startle was present at each training-to-test interval. This impression was confirmed by a two-way ANOVA on trial type and group (different retention intervals), which found a significant effect of trial type, reflecting fear-potentiated startle across the groups $[F(1,54)=86.63, p<.001]$. Importantly, however, there was no significant group $\times$ trial type inter- action $[F(5,54)=0.47]$. Paired $t$ tests found significant potentiated startle at each retention interval $[t(9)=3.68$, $4.63,6.04,3.26,5.66,2.45$, for 1-, 3-, 7-, 10-, 14-, and 28-day training-to-testing intervals, respectively; all ps < $.05]$. These results suggest that retention of aversive memories is unchanged over a 1 -month period with the parameters used, as measured with the potentiated startle paradigm.

\section{EXPERIMENT 2}

The magnitude of potentiation in Experiment 1B was similar at all retention intervals. However, the absolute magnitude of potentiation was lower than that routinely obtained with a greater number of CS-US pairings (Davis \& Astrachan, 1978; Davis et al., 1989). In Experiment 2, different footshock intensities were used in an attempt to improve the magnitude of potentiated startle. Both lower and higher shock intensities were employed, because a nonmonotonic relation previously has been demonstrated between shock intensity and magnitude of potentiated startle with more CS-US pairings (Davis \& Astrachan, 1978; Leaton \& Borszcz, 1985).

\section{Method}

Subjects

Sixty experimentally naive rats were used.

\section{Procedure}

The matching, training, and testing procedures, as well as the apparatus, were identical to those used in Experiment 1A. Five different groups of animals received either five presentations of the light alone $(n=10)$ or paired presentations of the light and footshock using shock intensities of either $0.4,0.6,1.0$, or $1.2 \mathrm{~mA}$ ( $n=10$, in each group). The animals were tested 7 days after training. Two additional groups of animals ( $n=5$, in each group) trained with shock intensities of either 0.4 or $1.0 \mathrm{~mA}$ were given 5 consecutive days of exposure to the testing context ( $30 \mathrm{~min} /$ day) prior to testing.

\section{Results and Discussion}

No reliable effect of the three different light-noise intervals was found $[F(2,90)=0.76]$. Subsequent analyses and data presentation were therefore performed on the average of the three light-noise intervals. The effect of varying the shock intensity is shown in Figure 3. The twoway ANOVA on trial type and group (different shock intensities) found a reliable group difference in startle amplitude $[F(4,45)=3.52, p<.05]$. The pattern of startle amplitudes seen in Figure 3 suggest that startle amplitude was nonmonotonically related to shock intensity. To evaluate this, the matching score for each rat was subtracted from the mean startle amplitude on the initial 10 noise bursts. The mean change scores $( \pm S E M)$ were -7.9 (8.5), 23.3 (7.2), 38.2 (13.9), 48.4 (15.0), and 34.7 (7.7), for the 0.0-, 0.4-, 0.6-, 1.0-, and 1.2-mA groups, respectively. These change scores were significantly different across groups $[F(4,45)=3.91, p<.01]$ and 


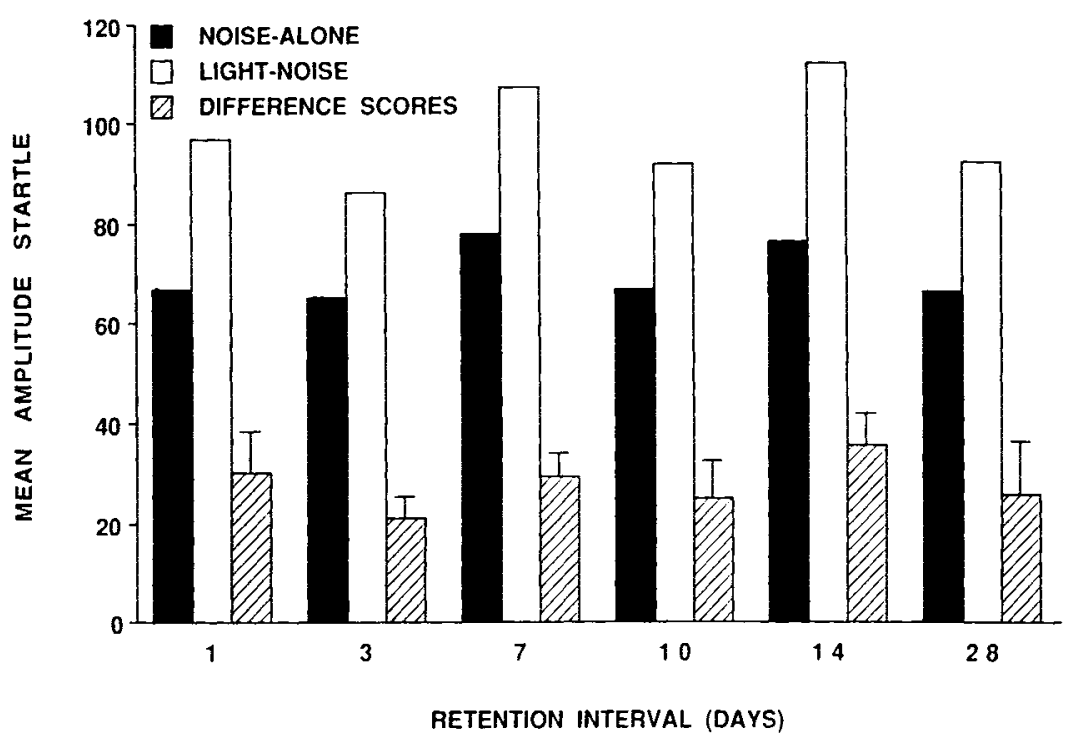

Figure 2. Mean amplitude startle on the noise-alone and light-noise test trials and difference scores $( \pm S E M)$ of rats exposed to five light-shock pairings tested at various retention intervals.

were related both linearly $[F(1,45)=10.15, p<.01]$ and quadratically $[F(1,45)=5.32, p<.05]$ to the shock intensity used in training. The initial two-way ANOVA further revealed a reliable group $\times$ trial type interaction, indicating different levels of potentiated startle across groups $[F(4,45)=2.81, p<.05]$. The results presented in Figure 3 suggest that the magnitude of potentiated startle was also nonmonotonically related to the shock intensity used in training and a quadratic trend on the difference scores was statistically reliable $[F(1,45)=8.92$, $p<.01]$, provided the light-alone group was used in the analysis. Furthermore, $t$ tests on each group found that only the $0.6-$ and $1.0-\mathrm{mA}$ shock groups showed signifi- cant potentiated startle $[t(9)=3.51$ and 4.67 , respectively; ps <.01].

The enhancement of the startle reflex during the initial 10 noise bursts was linearly and quadratically related to the training shock intensity, suggesting that some cues common to both the training and the testing apparati may gain excitatory strength and be responsible for the observed modification of startle. To test this hypothesis, two additional groups were trained and then tested following 5 consecutive days of exposure to the test context, which is a procedure known to reduce the excitatory value of contextual cues (Bouton \& Bolles, 1979; Bouton \& King, 1983). The data of the extinguished animals were com-

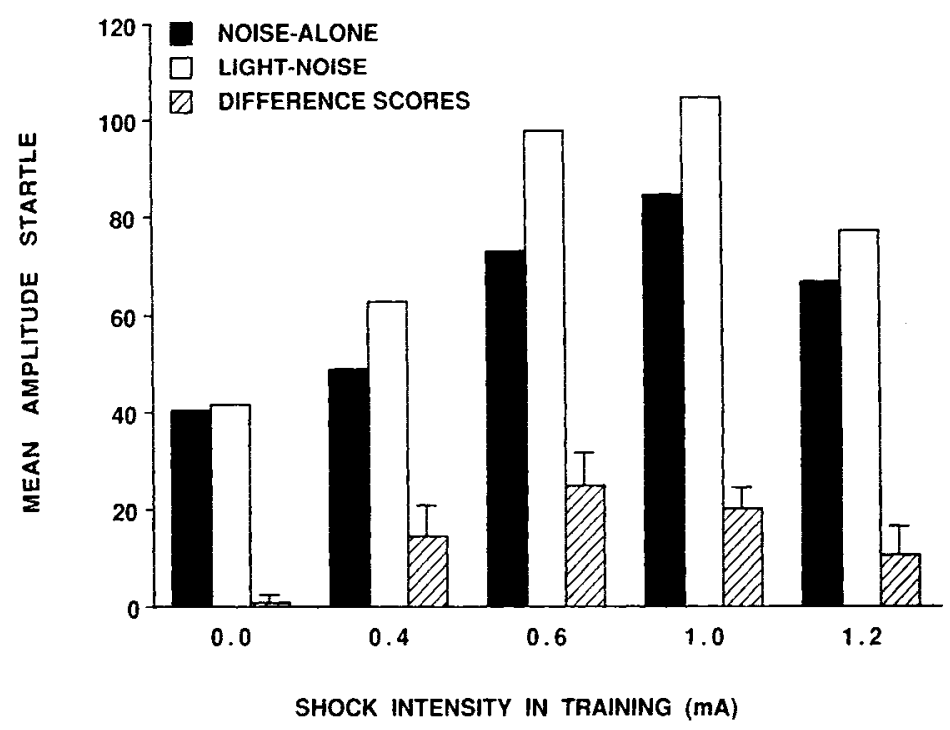

Figure 3. Mean amplitude startle on the noise-alone and light-noise test trials and difference scores $( \pm S E M)$ of rats exposed to five lights only or to five light-shock pairings at various shock intensity. 


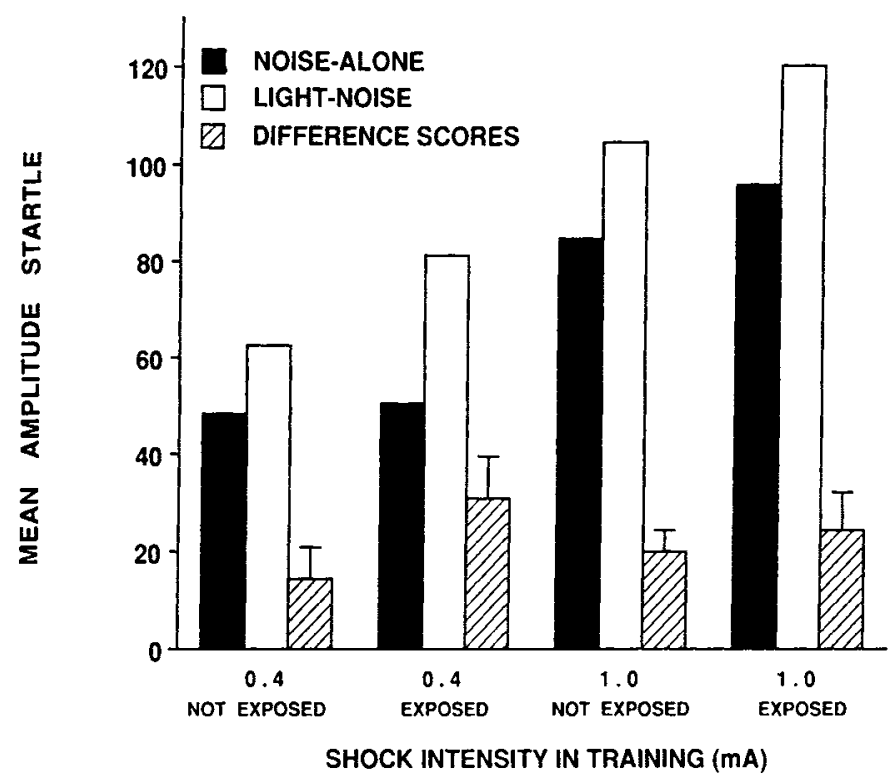

Figure 4. Mean amplitude startle on the noise-alone and light-noise test trials and difference scores $( \pm S E M)$ of rats given five light-shock pairings with either 0.4 or $1.0-\mathrm{mA}$ shock intensity and exposed or not exposed to the testing context for 5 days prior to testing. Note that the groups not exposed to the testing context are the same as those presented in Figure 3 at the corresponding training shock intensities, for comparison with the contextexposed animals.

pared with those of animals with a similar training history but not reintroduced to the test context prior to testing (see Figure 4). A two-way ANOVA on the difference scores with training shock intensity $(0.4 \mathrm{vs} .1 .0 \mathrm{~mA})$ as a between-subjects variable and context manipulation (exposure vs. no exposure) as another between-subjects variable found no significant effect of shock intensity $[F(1,26)$ $=0.01]$, context manipulation $[F(1,26)=2.27]$, or shock intensity $\times$ context manipulation interaction $[F(1,26)=$ $0.76]$. To better assess contextual effects, an additional two-way ANOVA on the change score means obtained by subtracting each animal's matching score from its mean startle amplitude during the initial 10 noise bursts was performed, with the same variables used in the analysis of the difference scores. The mean change scores $( \pm S E M)$ were 23.3 (7.2), 21.2 (10.1), 48.4 (15.0), and 56.2 (21.3), for the 0.4-mA not-exposed group, the 0.4-mA exposed group, the 1.0-mA not-exposed group, and the $1.0-\mathrm{mA}$ exposed group, respectively. This analysis revealed a significant effect of shock intensity $[F(1,26)=4.36, p<$ .05] but, importantly, no reliable context manipulation effect $[F(1,26)=0.04]$ or shock intensity $\times$ context manipulation interaction $[F(1,26)=0.12]$. These results indicate that the exposure manipulation prior to testing did not affect either the magnitude of potentiated startle or the enhancement of baseline startle produced by the prior shock experience in the training context.

\section{GENERAL DISCUSSION}

Fear-potentiated startle was reliably produced when five pairings of a light and footshock were presented at 2-min intervals. No potentiation was found with unpaired presentations of light and footshock (Experiment 1A) or following exposure to lights alone (Experiment 2), consistent with previous data using a larger number of light-footshock pairings and with the suggestion that the effect is associative. The magnitude of potentiated startle was comparable at all the retention intervals tested from 1 to 28 days. In general, potentiated startle was best using a $0.6-\mathrm{mA}$ footshock. Increasing or reducing the footshock intensity during training did not increase the magnitude of startle potentiation. Instead, there was an overall nonmonotonic increase in startle amplitude, as revealed by the differences on the light-noise versus noise-alone trials as a function of shock intensity. In addition, the mean startle amplitude on the initial 10 noise bursts also showed a nonmonotonic relationship to shock intensity. Interestingly, however, this effect was not generally observed in studies using many more training trials (e.g., Davis \& Astrachan, 1978; Leaton \& Borszcz, 1985).

The nonmonotonic increase in startle amplitude may reflect a general sensitizing effect of footshocks or the development of fear to contextual cues common to the training and testing situations. If conditioning to the train- 
ing contextual cues generalizes to the testing contextual cues, then procedures known to extinguish such conditioning should, at least, have attenuated startle enhancement. Five days of exposure to the testing context following training with $0.4-$ or $1.0-\mathrm{mA}$ shock intensities did not significantly reduce the increase in startle amplitude on the 10 initial noise bursts. It should be noted that these initial startle stimuli are the best estimate of fear to contextual cues because, at the beginning of testing, no CSs have yet been presented. The lack of effect observed is surprising because it has repeatedly been demonstrated that 5 days of context exposure (extinction) significantly reduce the sensitizing effect of initial acoustic startle stimuli in naive rats (Borszcz, Cranney, \& Leaton, 1989) or the excitatory value of contextual cues after conditioning with footshocks (Bouton \& Bolles, 1979; Bouton \& King, 1983; see also Lovibond, Preston, \& Mackintosh, 1984). It is possible that more than 5 days of exposure or extinction of the training context would have produced a different outcome. Therefore, it is still not clear whether the nonmonotonic startle amplitude increase in relation to shock intensity results from fear to situational cues or a more general nonassociative sensitization effect.

In addition to causing a change in baseline startle amplitude, there was some evidence for a nonmonotonic relationship between the absolute magnitude of potentiated startle and the intensity of shock used in training. These results cannot simply be accounted for by a general increase in startle amplitude because, at the highest shock intensity $(1.2 \mathrm{~mA})$, startle was lower than it was in groups trained with 0.6 and $1.0 \mathrm{~mA}$. Moreover, in studies using many more training trials, elevation of startle amplitude in the absence of the CS is generally not observed (Davis \& Astrachan, 1978; Leaton \& Borszcz, 1985). Together, these results indicate that, at moderate shock intensities, increasing the number of training trials may elevate the absolute magnitude of potentiated startle by reducing the amplitude of the startle reflex in the absence of the CS (e.g., Davis \& Astrachan, 1978; Leaton \& Borszcz, 1985; see also Davis et al., 1989). These observations are reminiscent of one of the predictions of the Rescorla and Wagner (1972) theory of Pavlovian conditioning, in which the excitatory value of contextual cues is assumed to decrease (relative to that of explicit CSs) when the number of training trials increases. However, with higher shock intensities, a relatively low magnitude of potentiated startle prevails when five or 20-30 training trials are employed (Davis \& Astrachan, 1978; Leaton \& Borszcz, 1985). This outcome is not expected from the Rescorla and Wagner model of conditioning. Moreover, this effect is not restricted to the potentiated startle paradigm; freezing has also been reported to be nonmonotonically related to shock intensity with three (see Fanselow, 1984, Experiment 3) or 30 training trials (Leaton \& Borszcz, 1985; see also the results of Sigmundi, Bouton, \& Bolles, 1980 , with a light CS). Additional studies have reported nonmonotonic relationships between shock intensity and shuttlebox avoidance (Levine, 1966; Moyer \& Korn, 1964).

The above observations do not readily distinguish between the interpretation that startle and some other measures are nonmonotonically related to fear or the alternative interpretation that fear is nonmonotonically related to shock intensity. However, studies assessing conditioned fear with the CER and other studies using escape and avoidance measures have usually found monotonic relationships between the number of training trials or shock intensity and the measure of fear (Annau \& Kamin, 1961; Brophy \& Tremblay, 1971; Estes \& Skinner, 1941; Goldstein, 1960; Kamin \& Brimer, 1963; W. R. McAllister \& D. E. McAllister, 1962). It therefore appears that potentiated startle is nonmonotonically related to fear per se. Additional data may support the interpretation that startle is nonmonotonically related to fear. For instance, Davis and Astrachan (1978) observed that animals trained with high shock intensity show higher potentiated startle in the course of extinction, relative to animals trained with moderate shock intensity (however, see Leaton \& Borszcz, 1985). In addition, animals trained with high shock intensity and treated with a mild stressor shortly before testing show high levels of startle potentiation, relative to animals not stressed before the potentiated startle test (Melia, Liang, Miserendino, \& Davis, 1989). These observations suggest that animals trained with high shock intensities can exhibit high levels of fear, but their test performance is normally inhibited, thereby masking the excitatory effects of CSs. These observations, taken collectively, may imply that an additional and qualitatively different conditioning process that inhibits the expression of some behavioral indices of fear may be engaged by high training shock intensities. The relationship between this inhibitory mechanism and other inhibitory processes documented in the learning literature is not known (e.g., Pavlov, 1928; see also Rescorla, 1985; Wagner \& Rescorla, 1972). In view of the above results, it might be informative to reexamine some of the response systems used to assess fear conditioning in relation to the effects produced by both shock intensity and the amount of training.

Finally, the magnitude of potentiated startle was essentially identical at all the training-to-testing intervals ranging from 1 to 28 days. These results are consistent with previous studies using a CER task, in which four CS-US pairings were sufficient to produce reliable CER $24 \mathrm{~h}$ and 90 days after training (Gleitman \& Holmes, 1967) and in which a single CS-US pairing produced reliable CER 29 days after training (Shurtleff \& Ayres, 1981). However, the present results contrast with some literature using avoidance measures as an index of fear conditioning, in which animals show poor performance after only a few days (D. E. McAllister \& W. R. McAllister, 1968; Quartermain \& Judge, 1983; Quartermain \& Jung, 1988; Spear et al., 1980). The relative permanence of potentiated startle in the present study may indicate rela- 
tively strong conditioned fear generated with relatively few training trials. These results also suggest that potentiated startle is more similar to CER tasks than it is to avoidance measures of fear, when used as an index of aversive memories produced with moderate shock intensities.

\section{REFERENCES}

Annau, Z., \& Kamin, L. (1961). The conditioned emotional response as a function of intensity of the US. Joumal of Comparative \& Physiological Psychology, 54, 282-287.

Blanchard, R. J., \& Blanchard, D. C. (1969). Crouching as an index of fear. Journal of Comparative \& Physiological Psychology, 67, 370-375.

Borszcz, G. S., Cranney, J., \& Leaton, R. N. (1989). Influence of long-term sensitization on long-term habituation of the acoustic startle response in rats: Central gray lesions, preexposure, and extinction. Joumal of Experimental Psychology: Animal Behavior Processes, $15,56-64$.

Bouton, M. E., \& Bolles, R. C. (1979). Contextual control of the extinction of conditioned fear. Learning \& Motivation, 10, 445-466.

Bouton, M. E., \& KING, D. A. (1983). Contextual control of the extinction of conditioned fear: Tests for the associative value of the context. Joumal of Experimental Psychology: Animal Behavior Processes, 9, 248-265.

BROPHY, J. C., \& TREMBLAY, A. M. (1971). One-trial CER as a function of shock intensity. Psychonomic Science, 25, 13-14.

Brown, J. S., Kalish, H. I., \& Farber, I. E. (1951). Conditioned fear as revealed by magnitude of startle response to an auditory stimulus. Journal of Experimental Psychology, 41, 317-328.

Cassella, J. V., \& DAvis, M. (1985). Fear-enhanced acoustic startle is not attenuated by acute or chronic imipramine treatment in rats. Psychopharmacology, 87, 278-282.

Cassella, J. V., \& DAVIs, M. (1986). The design and calibration of a startle measurement system. Physiology \& Behavior, 36, 377-383.

Davis, M., \& Astrachan, D. I. (1978). Conditioned fear and startle magnitude: Effects of different footshock or backshock intensities used in training. Journal of Experimental Psychology: Animal Behavior Processes, 4, 95-103.

Davis, M., Schlesinger, L. S., \& Sorenson, C. A. (1989). Temporal specificity of fear conditioning: Effects of different conditioned stimulus-unconditioned stimulus intervals on the fear-potentiated startle effect. Journal of Experimental Psychology: Animal Behavior Processes, 15, 295-310.

Estes, W. K., \& SkINNER, B. F. (1941). Some quantitative properties of anxiety. Journal of Experimental Psychology, 29, 390-400.

FANSELOW, M. S. (1984). Shock-induced analgesia on the formalin test: Effects of shock severity, naloxone, hypophysectomy, and associative variables. Behavioral Neuroscience, 98, 79-95.

FANSELOW, M. S., Bolles, R. C. (1979). Naloxone and shock-elicited freezing in the rat. Journal of Comparative \& Physiological Psychology, 93, 736-744.

FlaherTY, C. F. (1985). Animal learning and cognition. New York: Knopf.

GleItMAN, H. (1971). Forgetting of long-term memories in animals. In W. K. Honig \& P. H. R. James (Eds.), Animal memory (pp. 144). New York: Academic Press.

Gleitman, H., \& Holmes, P. A. (1967). Retention of incompletely learned CER in rats. Psychonomic Science, 7, 19-20.

GoLDSTEIN, M. L. (1960). Acquired drive strength as a joint function of shock intensity and number of acquisition trials. Journal of Experimental Psychology, 60, 349-358.
Kamin, L. J., \& Brimer, C. J. (1963). The effects of intensity of conditioned and unconditioned stimuli on a conditioned emotional response. Canadian Journal of Psychology, 17, 194-200.

LeAF, R. C., \& Muller, S. A. (1965). Simple method for CER conditioning and measurement. Psychological Reports, 17, 211-215.

Leaton, R. N., Borszcz, G. S. (1985). Potentiated startle: Its relation to freezing and shock intensity in rats. Journal of Experimental Psychology: Animal Behavior Processes, 11, 421-428.

LEVINE, S. (1966). UCS intensity and avoidance learning. Joumal of Experimental Psychology, 71, 163-164.

Lovibond, P. F., Preston, G. C., \& Mackintosh, N. J. (1984). Context specificity of conditioning, extinction, and latent inhibition. Jourmal of Experimental Psychology: Animal Behavior Processes, 10, 360-375.

MahoNEY, W. J., \& AYRES, J. J. B. (1976). One-trial simultaneous and backward fear conditioning as reflected in conditioned suppression of licking in rats. Animal Learning \& Behavior, 4, 357-362.

MCAllister, D. E., \& MCAllister, W. R. (1968). Forgetting of acquired fear. Journal of Comparative \& Physiological Psychology, 65, 352-355.

MCAllister, W. R., \& MCAllister, D. E. (1962). Postconditioning delay and intensity of shock as factors in the measurement of acquired fear. Journal of Experimental Psychology, 64, 110-116.

MCAllister, W. R., \& MCAllister, D. E. (1971). Behavioral measurement of conditioned fear. In F. R. Brush (Ed.), Aversive conditioning and learning (pp. 105-179). New York: Academic Press.

Melia, K. R., Liang, K. C., Miserendino, M. J. D., \& Davis, M. (1989). Reversal of a nonmonotonic relationship between footshock or CRF and the acoustic startle reflex by brief exposure to a mild stressor. Society for Neuroscience Abstracts, 15, 1069.

MOYER, K. E., \& KorN, J. H. (1964). Effect of UCS intensity on the acquisition and extinction of an avoidance response. Journal of $E x$ perimental Psychology, 67, 352-359.

Pavlov, I. P. (1928). Lectures on conditioned reflexes (W. H. Gantt, Trans.). New York: International Publishers.

Quartermain, D., \& JudGe, M. E. (1983). Retrieval enhancement in mice by pretest amphetamine injection after a long retention interval. Physiological Psychology, 11, 166-172.

Quartermain, D., \& Jung, H. (1989). Persistence of retrieval enhancement by amphetamine following scopolamine-induced amnesia. Pharmacology, Biochemistry \& Behavior, 33, 51-54.

Rescorla, R. A. (1985). Inhibition and facilitation. In R. R. Miller \& N. E. Spear (Eds.), Information processing in animals: Conditioned inhibition (pp. 299-326). Hillsdale, NJ: Erlbaum.

Rescorla, R. A., \& WAgner, A. R. (1972). A theory of Pavlovian conditioning: Variations in the effectiveness of reinforcement and nonreinforcement. In A. H. Black \& W. F. Prokasy (Eds.), Classical conditioning II (pp. 64-99). New York: Appleton-Century-Crofts.

ShURTLEF, D., \& AYres, J. J. B. (1981). One-trial backward excitatory fear conditioning in rats: Acquisition, retention, extinction, and spontaneous recovery. Animal Learning \& Behavior, 9, 65-74.

Sigmundi, R. A., Bouton, M. E., \& Bolles, R. C. (1980). Conditioned freezing in the rat as a function of shock intensity and CS modality. Bulletin of the Psychonomic Society, 15, 254-256.

SPEAR, N. E., Hamberg, J. M., \& Bryan, R. (1980). Forgetting of recently acquired or recently reactivated memories. Learning \& Motivation, 11, 456-475.

SPEAR, N. E., Miller, J. S., \& J AGIELO, J. A. (1990). Animal memory and learning. Annual Review of Psychology, 41, 169-211.

WAGNer, A. R., \& Rescorla, R. A. (1972). Inhibition of Pavlovian conditioning: Application of theory. In R. A. Boakes \& M. S. Halliday (Eds.), Inhibition and leaming (pp. 301-306). London: Academic Press.

(Manuscript received February 7, 1990; revision accepted for publication August 5, 1990.) 